\title{
"¿Quem é que não quer que a sua escola fique lá em cima?»: vozes que ecoam diante das avaliaçóes externas brasileiras aplicadas nas escolas da microrregiáo no Ubá / MG
}

\author{
ISABELA PEREIRA VICENTE \\ CRISTIANE APARECIDA BAQUIM ${ }^{*}$ \\ Universidade Federal de Viçosa, Brasil \\ HELOISA RAIMUNDA HERNECK ${ }^{* * *}$
}

Universidade Federal do Espírito Santo (UFES), Brasil

Recibido el 14-11-2015; primera evaluación el 26-07-2016;

segunda evaluación el 29-08--2016; aceptado el 05-09-2016

* Graduada em Pedagogia pela Universidade Federal de Viçosa. Atuou com atividades de monitoria, na qualidade de monitora, e como bolsista do Programa Institucional de Bolsas de Iniciação a Docência (PIBID). Foi voluntária e bolsista em projetos de extensão com temáticas interdisciplinares envolvendo educomunicação, cultura, direitos humanos, justiça, educação e saúde. E também foi bolsista do Programa Institucional de Bolsas de Iniciação Científica (PIBIC) do Conselho Nacional de Desenvolvimento Científico e Tecnológico (CNPq) pesquisando os seguintes temas: educação, formação docente e políticas públicas educacionais. Contacto: belinhavicente@gmail.com

** Graduada em Pedagogia pela Universidade Federal de Viçosa, mestre e doutora em Educação pela Universidade Federal de São Carlos, pós-doutoranda em educação pela Universidade do Porto/Portugal. Atualmente é docente da Universidade Federal de Viçosa, na área de Gestáo da Educação, tendo já assumido cargos como Coordenadora do curso de Pedagogia, Coordenadora institucional do Laboratório Interdisciplinar de Formação de Educadores, Coordenadora Pedagógica do Programa de Apoio aos Dirigentes Municipais de Educação e membro do Conselho Municipal de Educaçáo da cidade de Viçosa/MG. Desenvolve e orienta pesquisas especialmente na área de Políticas Educacionais e Legislação de Ensino. Contacto: cristiane. baquim@ufv.brou cbaquim@hotmail.com

*** Pós-doutorado na Universidade Federal do Espírito Santo, com pesquisa desenvolvida em Coimbra/Portugal na área de Formaçáo Continuada de professores e sexualidade. Doutorado e Mestrado em Educação na Universidade Federal de São Carlos. Graduou em Pedagogia pela Universidade Federal de Viçosa, onde atualmente atua como professora adjunta no Departamento de Educação. Orienta pesquisas no Mestrado em Educação da UFV com projetos nas áreas de Formação de Professores, Gênero e Cotidianos, Rede Social, Políticas Educacionais na linha de pesquisa Memória, Instituições e Subjetividade. Contacto: hherneck@ufv.br 


\section{Resumo}

O objetivo do artigo é apresentar os resultados de uma pesquisa que analisou o impacto das avaliaçóes externas no trabalho docente em escolas públicas da microrregião de Ubá (MRUbá), Minas Gerais. A metodologia contou com uma investigação realizada em três escolas, observaçóes in loco, entrevistas semiestruturadas com professoras, pesquisa bibliográfica sobre o tema e análise qualitativa dos dados. As «vozes» que ecoaram das escolas sinalizaram para a lógica da prestação de contas, da responsabilização, das pressóes por resultados, da (des) crença no IDEB, dos aspectos relativos à competição, dentre outros. Os dados nos possibilitaram perceber que os professores são muito afetados pelo atual modelo avaliativo, cujos mecanismos de mensuração o culpabilizam e também à escola, além de gerarem rankings que estáo cada vez mais reforçando um ambiente competitivo.

Palavras-chave: trabalho docente, avaliaçōes externas, políticas educacionais, Microrregião de Ubá-MG.

"Who would not want your school get up there?»: Voices that echo on the Brazilian external evaluations applied in the micro-region schools of Ubá / MG

\section{Abstract}

The purpose of this article is to present the results of a survey that examined the impact of external evaluations in teaching in public schools of micro-region of Ubá (MRUbá), Minas Gerais. The methodology included an investigation into three schools, on-site observations, semi-structured interviews with teachers, literature on the subject and qualitative data analysis. The «voices» that echoed the schools signaled to the logic of accountability, accountability, the pressure for results, the (dis) belief in IDEB, of aspects relating to competition, among others. The data enabled us to realize that teachers are greatly affected by the current evaluation model, whose measurement mechanisms the blaming and also to school, besides generating rankings that are increasingly reinforcing a competitive environment.

Keywords: teaching work, external evaluations, educational policies, micro-region of Ubá-MG.

“¿Quién no querría que su escuela llegue a la cima?»: voces que hacen eco en las evaluaciones externas brasileñas aplicadas en las escuelas de la microrregión de Ubá/MG

\section{RESUMEN}

El objetivo de este trabajo es presentar los resultados de una investigación que analizó el impacto de las evaluaciones externas en el trabajo docente en escuelas públicas de la microrregión de Ubá (MRUbá), Minas Gerais. En la metodología se incluyen la investigación realizada en tres escuelas, observaciones in loco, entrevistas 
semi-estructuradas con profesoras, la literatura sobre el tema y el análisis cualitativo de los datos. Las «voces» que resonaron de las escuelas señalaron a la lógica de la rendición de cuentas, de la responsabilidad, de la presión por resultados, de la (des)creencia en el IDEB, de los aspectos relativos a la competición, entre otros. Los datos nos posibilitaron darnos cuenta de que los profesores se ven muy perjudicados por el actual modelo evaluativo cuyos mecanismos de medición los culpabilizan a ellos y aún a las escuelas, además de generarse rankings que refuerzan cada vez más un ambiente competitivo.

Palabras clave: trabajo docente, evaluaciones externas, políticas educacionales, Microrregión de Ubá-MG.

\section{INTRODUÇÃo}

O objetivo do presente artigo é apresentar os resultados de uma pesquisa que analisou o impacto das avaliaçóes externas no trabalho docente em escolas públicas da microrregião de Ubá (MRUbá), Minas Gerais. Procuramos identificar as dificuldades dos docentes em relação à compreensão do processo avaliativo externo, desde a leitura dos resultados e transposição dos dados quantitativos até as práticas que visaram à melhoria da qualidade do processo ensino e aprendizagem.

Ao contrário de pesquisas sobre avaliações externas em cenários muito abrangentes, nossa pesquisa buscou evidenciar aspectos mais específicos que permeiam o cotidiano escolar, fazendo uma investigação mais próxima da realidade dos professores, já que uma pesquisa anterior, de Brasiel e Baquim (2014), apontou para futuras investigaçôes sobre a temática das avaliaçôes na MRUbá.

A citada pesquisa mapeou o contexto dos resultados alcançados pelas escolas que oferecem os anos iniciais do Ensino Fundamental da MRUbá na Prova Brasil e no Sistema Mineiro de Avaliação da Educação (SIMAVE), identificando três instituiçóes com índices diferentes (baixo, mediano e alto), e sugerindo outros estudos acerca da compreensão de como os docentes que nelas atuavam interpretavam os resultados alcançados, e se alteravam suas práticas pedagógicas em função disso. Visando responder a essa problemática, realizamos uma pesquisa qualitativa que contou com observaçôes in loco, enfocando o "chão da escola». Em dias de aplicação de provas, procedemos a diálogos orientados com os funcionários e com a equipe gestora, e realizamos entrevistas semiestruturadas com seis professoras das três escolas localizadas em diferentes municípios que compóem a MRUbá. 
O pressuposto é o de que as políticas educacionais com foco nas avaliaçóes externas promovem uma mudança na prática pedagógica, alterando concepçóes importantes como o currículo, processos de ensino e aprendizagem, planejamento, formação de professores e, especialmente, a qualidade do ensino. Tal influência é enfatizada nos estudos de Souza e Oliveira (2010, p. 796), que apontam questionamentos sobre o papel do Estado, pois a «discussão da avaliação de sistemas abrange um amplo leque de questóes de natureza técnica e, para além delas, implicaçôes de ordem política, pois que está intimamente vinculada às políticas públicas de educação». Assim, para prosseguirmos nesta análise, é importante elucidarmos o conceito de avaliação enquanto referência política.

\section{O ConCeito de aValiaçáo e SeUS Desdobramentos}

Com base no referencial teórico utilizado, é possível perceber que as avaliaçóes sáo referentes importantes quando se trata de questóes relativas ao ensino e aprendizagem. Nesse sentido, destacamos as contribuiçóes de Afonso (2010) que afirma ser o termo avaliação polissêmico. Como as diversas formas de avaliar fazem parte de um conjunto abrangido pelo termo «avaliação educacional» (Afonso, 2014), torna-se conveniente que os contextos de sua utilização sejam evidenciados nos cenários em que emerge.

Levando em consideração esses cenários, diversos são os autores que contribuem para essa discussão. Chueiri (2008) busca estabelecer relação entre as concepçóes pedagógicas e o contexto da avaliação no espaço escolar, defendendo a avaliação como inerente ao ser humano, pois faz parte de todo nosso cotidiano; é determinada por valores e normas sociais, que são formas de construção da nossa sociedade; são valores que estão enraizados e que, portanto, pode servir tanto para a manutenção do sistema, quanto para a transformação de um padrão previamente estabelecido (Villas Boas, 1998 apud Chueiri, 2008).

Já Vianna (1995) apresenta suposiçôes sobre a teoria e a prática da avaliação educacional em diferentes perspectivas históricas. Analisando o processo avaliativo nos Estados Unidos e Inglaterra, o autor abrange as implicaçóes da avaliação no Brasil, a começar pela década de 1960. Para ele, a avaliação se faz presente em diferentes formas de abordagens, especialmente associadas ao processo educativo.

Logo, a utilização do termo avaliação educacional, se utilizado sem suas especificaçóes e sem contexto evidenciado, pode sugerir um sentido muito restrito ou limitado, referindo-se somente à avaliação pedagógica, de rendimento e de desempenho escolar dos alunos. 
De acordo com o Centro de Políticas Públicas e Avaliação da Educação da Faculdade de Educação da Universidade Federal de Juiz de Fora (CAED/ $(U F J F)^{1}$, a definição de avaliação educacional é compreendida como um processo que se relaciona com a

produção de informaçóes sobre determinada realidade e está bastante presente no cotidiano escolar: tradicionalmente, os professores aferem o aprendizado dos seus alunos através de diversos instrumentos (observaçóes, registros, provas etc.) e indicam, a partir daí, o que precisa ser feito para que eles tenham condiçôes de avançar no sistema escolar (CAED/UFJF, 2014, n.p.).

Seguindo essa compreensão, o CAED/UFJF (2014) aponta as avaliaçôes subdivididas nas cinco dimensóes seguintes: a avaliação diagnóstica, que pode ser compreendida como qualquer ação avaliativa realizada no início do processo de aprendizagem; a avaliação interna, que permite que o professor possa verificar a ocorrência do processo de ensino aprendizagem em sua sala de aula por meio de provas, registros e auto avaliações; a avaliação formativa, que é caracterizada por possibilitar proximidade de diálogo entre o professor e o aluno, uma vez que essa não tem finalidade probatória; a avaliação somativa, que visa a classificação com a perspectiva de conclusão para certificar. Por fim, a avaliação externa, ou avaliação em larga escala, supóe que a escola será analisada por agentes externos a ela.

O CAED (2014, n.p.) afirma que o objetivo das avaliações externas são a busca para «assegurar a qualidade da Educação, fortalecendo o direito a uma educação de qualidade a todos os alunos». Porém, esta qualidade tem como base os resultados dos diversos testes aplicados às escolas, que produzem uma realidade, muitas vezes performativa, de forma a atender aos resultados esperados.

Faz-se necessário ressaltar, então, a perspectiva de qualidade ${ }^{2}$ educacional proposta por Antonio Gramsci (2001), a partir da qual nos pautamos para empreender esta discussão. O ideal de qualidade proposto por Gramsci a partir da escola unitária difere-se da forma como tal conceito é sugerido na maioria dos documentos oficiais que tratam das avaliaçóes externas. Por

\footnotetext{
1 Órgão responsável pela elaboraçáo e aplicação das avaliaçôes externas em Minas Gerais e em outros estados brasileiros.

2 Gramsci idealizava um novo tipo de escola, onde se formassem pessoas com cultura ampla, que entendessem o mundo e a sociedade com base em sua história. Uma formaçáo mais crítica e humana e não aquela que reproduzia a dominação de classes e que se pautava na formação propedêutica. Ele propunha uma escola unitária, onde houvesse a formação crítica, emancipatória e política. Uma formação que tinha como princípio educativo o trabalho, a disciplina e a dedicação. Uma educação que elevasse o sujeito do senso comum para a consciência filosófica (cf. Gramsci, 2001).
} 
exemplo, o Art. 3 da Portaria no s 482, de 7 de junho de 2013, que dispóe sobre o Sistema de Avaliação da Educaçáo Básica - SAEB, informa que os objetivos da ANRESC/Prova Brasil são:

I - avaliar a qualidade do ensino ministrado nas escolas, de forma que cada unidade escolar receba o resultado global;

$[\ldots]$

III - contribuir para o desenvolvimento, em todos os níveis educativos, de uma cultura avaliativa que estimule a melhoria dos padrōes de qualidade e equidade da educaçáo brasileira e adequados controles sociais de seus resultados (BRASIL, 2013, n.p.).

Há, portanto, uma nítida sugestão da melhoria da qualidade em decorrência da aplicação das avaliaçóes e dos controles sociais a serem exercidos sobre o trabalho da escola.

A definição de Freitas sobre as avaliaçóes externas nos ajuda a perceber sua relação com o cenário das políticas públicas em educação. Segundo ele, a finalidade dessas avaliaçôes consiste em informar aos gestores das várias instâncias do sistema educacional e da escola, professores e a sociedade em geral em que medida as políticas educacionais estão sendo desenvolvidas». Essas políticas devem esclarecer, sobretudo, se o processo educativo está alcançando os objetivos desejados, subsidiando, assim, a formulação, a manutenção ou a revisão de políticas públicas definidas para a educação (Freitas, 2009, p. 54).

Percebe-se que a finalidade das avaliaçóes externas evidencia a sua ligação com as políticas públicas e a qualidade da educação, passando a compor o quadro de reformas em âmbito nacional, estadual e municipal, e o trabalho docente começa a pautar-se pelas suas referências. Portanto, é preciso compreender o contexto em que estão inseridas e seu surgimento numa dimensão político-ideológica.

\section{O CONTEXTO BRASILEIRO}

O sistema educacional brasileiro ainda é tributário da forte dominação pela qual o país passou. O processo de colonização e as desigualdades ocasionadas por um processo tardio de escolarizaçáo impingiram dificuldades que afetam, até hoje, o nosso processo de escolarização. Ou seja, a desigualdade em relação ao acesso à escola reproduz a desigualdade também no que se refere à permanência no processo educacional (Duarte, 2010).

É importante destacar que as décadas de 1980 e 1990 foram favoráveis a muitas reformas educacionais, pois naquele período a opçáo política 
pela introduçâo dos preceitos neoliberais, favorecida pela dominação ideológica amplamente disseminada e pela abertura internacional de mercado, consolidou a ideia da necessidade de implementação de um Estado Mínimo (Duarte, 2010). Segundo Dallari (2007), nesse modelo é mais importante que o campo de atuação e intervençáo do Estado seja mais o mercado do que as políticas públicas sociais.

Assim, sob o discurso de centralização e descentralização, as políticas educacionais passaram a ser reconfiguradas, com a educação básica ofertada pelos Estados e Munícipios sendo regulada pelo Ministério da Educação (MEC), que concentra esse poder utilizando-se das avaliações externas. Estas têm como foco medir, a partir de um mesmo instrumento, o desempenho dos alunos, desconsiderando aspectos subjetivos referentes às crianças e aos jovens e os contextos de aprendizagem. É essa avaliação também a medida que serve para classificar escolas e professores como mais ou menos eficientes de acordo com um índice desenvolvido para esse fim, o Índice de Desenvolvimento da Educação Básica (IDEB).

Um aspecto importante para compreender esta contextualização é a descentralização financeira promovida pelo Estado nos anos 1990, que visava favorecer os processos pedagógicos das instituiçôes escolares, ampliando, com isso, a autonomia dos municípios, como nos aponta Dallari (2007). Porém, as escolas viram-se incumbidas de realizar funçôes contábeis e administrativas com as quais não estavam habituadas, sem serem capacitadas para tal. Os gestores passaram a ter uma função mais gerencialista, de acordo com os modelos da iniciativa privada, com metas e orçamentos a serem administrados.

Assim, a suposta autonomia atribuída às escolas reverteu-se apenas em mais trabalho burocrático, compatível com uma lógica de mercado que não combina com o sentido social do trabalho da escola, nem com a consolidaçáo das práticas realizadas pelos professores. Sobre esta questão, Calderano (2012) aponta que as avaliaçôes externas, além de controlarem o currículo formal, controlam também a autonomia do professor ao exercer seu trabalho. Ou seja, elas impactam nos aspectos pedagógicos, estabelecem um currículo, modificam o cotidiano da escola e, por consequência, interferem no processo de escolarização desenvolvido, gerando as condiçóes fundamentais para implementação da privatização e mercadorização da educação (Ribeiro, 2002).

É justamente nesse sentido que Afonso (1999) define o mercado ou «quase mercado ${ }^{3}$ como uma "criação política, concebida para fins políticos», sendo

3 Na definição de Le Grand - um dos autores que tem vindo a discutir a criação de quase-mercados no âmbito do Estado-providência -, quase-mercados são mercados porque substituem 
cuidadosamente regulado pelo próprio Estado. Distinguindo os dois campos - educação e mercado - é evidente que no campo educacional a prática da compra dos consumidores não se expressa em termos monetários, mas, considerando o mercado como premissa já definida por Roger Dale, a semelhança entre ambos é nítida quando se faz necessária a introdução de um currículo e uma avaliaçáo em nível nacional, onde o governo está preocupado com «a necessidade de elevar os níveis educacionais - o que é, afinal, a principal preocupação do mercado» (Dale apud Afonso, 1999, p. 145).

Ainda em relação ao processo de centralização/descentralização, são transferidas inúmeras responsabilidades aos estados, municípios, escolas e seus profissionais. Apesar de o Estado centralizar a questão curricular, elaborando e aplicando diretrizes curriculares nacionais para todos os campos do conhecimento e também reforçando o Programa Nacional do Livro Didático (PNLD), ele afirma dar autonomia para as escolas trabalharem numa perspectiva de atendimento às diversidades regionais. Entretanto, se as escolas buscam diversificar o currículo para atender à sua realidade, as avaliaçóes externas induzem a uma adequação ao currículo determinado, consolidando práticas docentes voltadas para a aplicaçáo das provas e para o cumprimento de metas quantitativas, como asseguram as declaraçóes das professoras entrevistadas, as quais veremos adiante.

\section{Procedimentos metodológicos}

Para compreender como o professor tem sido afetado pelo processo de avaliação externa aplicada aos alunos nas escolas, é necessário que o pesquisador esteja com o seu olhar voltado para o cotidiano em que estas avaliaçóes acontecem, atento aos detalhes e às movimentaçóes inerentes a esse processo. Desta forma, optamos por utilizar mais de um instrumento para a produçáo dos dados, de modo que favorecesse considerar o espaço escolar numa perspectiva mais ampliada.

Para a leitura dos dados fizemos a opção por realizar um estudo descritivo analítico, de natureza qualitativa, uma vez que segundo Bogdan e Biklen (1994), ainda que sejam muitas as formas de investigação qualitativa, todas partilham, até certo ponto, o objetivo de compreender os sujeitos com base nos seus pontos de vista, mesmo que o ponto de vista do outro se mostre como

o monopólio dos fornecedores do Estado por uma diversidade de fornecedores independentes e competitivos; são quase porque diferem dos mercados convencionais em aspectos importantes (Afonso, 1999, p. 143). 
um problema, pois o pesquisador, ao inserir-se no campo de investigação, também não é um indivíduo neutro.

A opçáo pela observação do espaço escolar em dia de aplicação das provas deveu-se ao fato de considerar ser este um momento singular e atravessado por momentos partilhados e significados próprios para as pessoas que ali trabalham. E em se tratando de uma pesquisa qualitativa, consideramos que as açóes e reaçôes dos professores teriam muito a nos mostrar neste dia, pois observar é aplicar os sentidos a um objeto para obter conhecimento sobre ele. Realizamos uma observação espontânea, informal, simples, livre ou ocasional, o que segundo Lakatos e Marconi (2010), caracteriza as observaçóes sem o emprego de qualquer técnica ou instrumento, sem planejamento, sem controle e sem quesitos observacionais previamente elaborados. Em se tratando de um dia diferente para a escola, não sabíamos bem o que encontraríamos e o que seria importante para a nossa pesquisa - por isso a opçáo por este tipo de observaçáo. A intençáo era captar o que nossos olhos fossem capazes de relacionar com a pesquisa.

Paralelamente às observaçóes, iniciamos as entrevistas, das quais participaram seis professoras no âmbito das três escolas, sendo que três entrevistas foram gravadas e depois transcritas, e três não, por opção das entrevistadas.

A opção por trabalhar com entrevistas ocorreu pelo fato de serem consideradas uma das "principais técnicas de trabalho em quase todos os tipos de pesquisa utilizados em ciências sociais» (André e Ludke, 1986, p. 33). Segundo Bogdan e Bilklen (1994), em todas as situaçóes a entrevista é utilizada para recolher dados descritivos na linguagem do próprio sujeito, permitindo ao investigador desenvolver intuitivamente uma ideia sobre a maneira como os sujeitos interpretam aspectos do mundo. Portanto, foi uma técnica muito adequada para compreender como as professoras percebiam as avaliaçóes externas.

Para a análise dos resultados, optamos por uma descrição analítica mais geral à luz do referencial mobilizado, sem identificar as professoras e as escolas às quais elas pertenciam, uma vez que o que nos interessava não era realizar uma análise comparativa entre as três escolas, mas identificar a percepção das professoras acerca do nosso objeto de estudo.

\section{Por dentro dos muros das escolas}

Nossa pretensão, para além de fazer uma distinção métrica entre as escolas onde realizamos o presente trabalho, é evidenciar que as instituiçóes se diferem muito em diversos aspectos, e não somente em relação às notas obtidas, sendo esse contexto menosprezado pelo atual modelo avaliativo praticado no Brasil. 
Vale ressaltar mais uma vez que, quando nos referimos aos índices - menor, mediano e maior -, nos remetemos ao trabalho de Brasiel e Baquim (2014), que nos apontam para a média ponderada entre os resultados dessas instituiçôes na Prova Brasil de 2007, 2009, 2011; e do Proeb/SIMAVE de 2010, 2011, 2012.

Foi possível perceber que a instituição com a menor média apresenta uma realidade muito específica de desmotivação por parte da direção da escola, com quem fizemos nossos primeiros contatos de pesquisa. Foi inevitável não perceber essa desmotivação presente, inclusive, nos espaços intramuros escolares. Localizada em um bairro afastado do centro da cidade, a população atendida pela instituição reside numa região periférica do município, num contexto socioeconômico e educacional mais precário. Os profissionais que nela atuam, ao falarem informalmente de seu trabalho, nos informam que se sentem responsabilizados pelos resultados negativos alcançados pela escola e como isso afeta a autoestima de todos os profissionais envolvidos; entretanto, informam também que o contexto menos favorecido dos alunos impacta decisivamente no trabalho realizado e, por consequência, nas avaliaçóes e nos resultados decorrentes.

Ainda assim, as entrevistas realizadas na escola demonstraram um posicionamento muito crítico das docentes em relaçáo à política de avaliaçóes externas, o que mobilizou nosso próprio (re) pensar sobre os aspectos encobertos pelo ideário de qualidade suposto nos índices.

Nessa escola participamos da rotina no dia da aplicação da ANA (Avaliação Nacional da Alfabetização), que é feita por um agente externo à escola. O professor regente da sala não pode sequer ver a prova, nem tirar as dúvidas dos seus alunos. Nesse dia, uma professora relatou a angústia que era presenciar a tensão dos seus próprios alunos que também se refletia nela:

Você viu só como é que funciona? Não tem condiçôes! Coitados dos meus alunos, eu morro de dó. O pior de tudo é que eu fico muito tensa e não consigo passar tranquilidade pra eles. É um absurdo outra pessoa que eles nem tem contato invadir a minha sala de aula e querer ter o controle da situação. Total absurdo, isso sim!

Essa angústia, a nosso ver, somatiza tensóes que, juntamente com outros fatores estressantes típicos dessa profissão, pode gerar o descontentamento, a baixa autoestima, o sentimento de não reconhecimento de seu estatuto profissional, a falta de crença nas políticas voltadas para melhorar a qualidade da aprendizagem e até o adoecimento docente. 
A instituição de índice mediano nos possibilitou mais abertura para a realização das observaçóes em dias de aplicação de algumas provas do que para as entrevistas. Mas os dados produzidos nessa instituição foram muito relevantes, pois tivemos contato com agentes externos à escola no dia da aplicação do Programa de Avaliação da Rede Pública de Educação Básica (PROEB). Foi possível perceber, por exemplo, a tensáo ocasionada em todo o ambiente escolar, o nervosismo de algumas professoras, de toda a gestão da escola, e até de alguns funcionários que ficaram incumbidos de buscar em casa os alunos que ainda estavam ausentes.

Uma questão inusitada aconteceu quando tivemos contato com uma professora que aguardava ansiosamente a finalização da prova com os alunos de sua turma e nos relatava seu ponto de vista sobre o tipo de prova que estava sendo aplicada naquele dia. Ao nos questionar sobre o tema que investigaríamos na realidade daquela instituição, ela relatou que sua ansiedade e preocupaçáo, naquele momento, tinha como causas: a) o medo de que seus alunos não fossem bem na avaliação e; b) o medo das consequências dos resultados, porque segundo ela «a culpa vai cair é sobre mim. Se eles forem bons, que bom, sinal de que sou uma ótima professora; se eles não conseguirem alcançar um bom resultado, vão começar a me olhar de cara feia». Como dissemos acima, são tensões que vão se diluindo na dinâmica da vida escolar, mas que se acumulam no inconsciente do profissional que está sendo «testado».

Nesta mesma instituição, a cozinheira lamentava sobre o fato de saber que, mesmo os resultados da escola sendo bons, sua amiga - professora da instituição - estava sempre insatisfeita, pois a realidade da sala de aula dela era completamente diferente das outras turmas da escola que seguiam um padrão de qualidade «melhor», uma vez que a sala de aula da professora tinha um processo de aprendizagem mais «lento» do que as turmas mais «avançadas» da escola. Isso demonstra que não apenas o professor é afetado pela lógica comparativa, mas todos os profissionais da escola.

A análise que fazemos sobre essa questão perpassa a responsabilização dos professores e alcança as cobranças que esses profissionais fazem sobre a sua própria atuação enquanto docentes. Não bastasse a pressão por bons resultados que já recai sobre eles, se cobram também pela capacidade de aprendizagem de cada um de seus alunos.

Novamente, é preciso repensar onde está a origem dos termos que se tornaram recorrentes no ambiente escolar, ao mencionar o processo de aprendizagem como lento e avançado. O poder coercitivo dos resultados das avaliaçóes em larga escala faz com que sejam criados referenciais de medida que, inconscientemente, já estão se naturalizando no espaço escolar e sendo 
utilizados como uma escala para medir o desempenho dos estudantes, apenas focando no «benchmarking métrico» (Sarrico, 2014, p. 276).

A terceira instituição analisada detém o maior índice dentre as investigadas. Em comparação com as escolas anteriores, nesta evidencia-se uma maior organização da gestáo da escola com relação às avaliaçôes externas, internas e diagnósticas.

Situada numa região mais central da cidade, atende a muitos alunos provenientes de uma classe média mais favorecida que as demais escolas, incluindo filhos de professores e funcionários públicos da cidade. Segundo a gestora, o receio de perder a vaga na instituição, que é táo bem avaliada, faz com que a família dos alunos participe mais de sua vida escolar, o que favorece o processo de aprendizagem. É uma escola que também conta com um quadro de profissionais mais estáveis, muitos deles com mais de 10 anos de trabalho no local, o que os torna mais envolvidos e comprometidos com os resultados alcançados. Nenhuma das entrevistadas nessa escola permitiu a gravaçáo das entrevistas e todas sugeriram que as questôes fossem feitas na própria sala de aula, na presença dos alunos.

Apesar do contexto mais favorável e que, a nosso ver, tem relação direta com os resultados métricos positivos alcançados pela escola, ainda assim, no dia da observação da aplicação de provas a tensão no ambiente escolar era sentida, principalmente, pelas professoras. O desconforto no ambiente escolar nos chamou muito a atençáo no dia das avaliaçóes em que agentes externos à escola estariam presentes. É claro que a nossa presença na instituição também desconfigurou a rotina da escola nos determinados dias, mas a tensão decorrente de ter uma pessoa externa avaliando a aprendizagem e, por consequência, o trabalho docente, é muito grande, e foi percebida em todos os agentes da escola, incluindo os alunos e os funcionários que nela atuam.

Um dado interessante diz respeito à relação observada entre a permanência do professor em determinada instituição e o resultado que esta instituição alcança no IDEB. As escolas que apresentam índices mais baixos parecem ter maior propensão a ter mais rotatividade de docentes, o que acaba interferindo, por consequência, na qualidade do ensino, reforçando um ciclo vicioso difícil de quebrar. Esse foi um dado evidenciado em nossa observação da realidade escolar que não foi citado por nenhum docente nas entrevistas, pois parece ser um efeito perverso já subjetivado pelos profissionais. Portanto, percebemos mais uma vez o que Calderano (2012) aponta em suas pesquisas: o fato de que as avaliaçóes externas e seus resultados estáo cada vez mais presentes nas escolas, porém, não são favoráveis à qualidade do ensino ofertado. 


\section{OUVINDO AS VOZES QUE ECOAM DAS ESCOLAS}

Inicialmente, cabe destacar a dinâmica que envolveu a maioria das entrevistas: foram realizadas na sala de aula enquanto os alunos faziam algum tipo de atividade no mesmo local. Por diversas vezes, a entrevista tinha que ser adiada para que as professoras interviessem na disciplina ou tirassem alguma dúvida dos alunos. Esse era um fator um pouco desconfortável para as professoras, e que também gerou situaçóes de tensão no ambiente em que realizamos as entrevistas, mas ainda assim foi possível captar o posicionamento das docentes em relação às avaliaçóes.

Para contextualizar a questão da docência e analisar a percepção das professoras a respeito das avaliaçóes externas, buscamos em Calderano (2012) os elementos referenciais de que precisávamos. Um dos aspectos de nossa pesquisa que se assemelhou a esse referencial são os indicativos de responsabilização que estão presentes na perspectiva de todas as docentes entrevistadas. Ao questionarmos uma das professoras entrevistadas sobre a forma como ela interpreta o Índice de Desenvolvimento da Educaçáo Básica (IDEB), a mesma declarou que, em relação aos resultados, acaba virando uma competição, pois «aí ninguém quer ficar pra trás». A declaração da professora vai ao encontro do que a literatura (cf. Afonso, 1999 e 2009) nos apresenta sobre as lógicas de disputa no campo econômico, mas que interferem de forma significativa no campo educacional.

Ainda sobre essa afirmação fica salientado que o accountability que Afonso (2009) tanto evidencia em seus estudos também é referendado pelas práticas avaliativas brasileiras. $\mathrm{O}$ autor aponta que esse conceito está associado a três dimensões autônomas, sendo elas: a avaliação, a prestação de contas e a responsabilização. O sistema de accountability implica em relaçóes muito complexas, e foi possível perceber isso na dimensão de responsabilização no caso das professoras desse estudo, «uma vez que esses profissionais têm que prestar contas às várias instâncias hierárquicas, incluindo também outros elementos da comunidade educativa» (Afonso, 2009, p. 15). Tal lógica complexa é anunciada na fala de uma professora quando ela se refere à forma como se sente pressionada: «Olha a responsabilidade que fica nas minhas mãos».

Logo em seguida, ela acrescenta sobre a competição gerada por essa responsabilização docente: "[...] oh gente, quem é que não quer que a sua escola fique lá em cima? Quem é que não quer? Aí vira competição porque ninguém quer ficar pra trás». A partir dessa fala, percebe-se o que Santos (2013) considera como proposição nesse tipo de estudo: as avaliaçóes externas apontam para um efetivo ranqueamento entre as escolas e "uma educação capaz de formar profissionais capazes de competir no mercado de trabalho" (Afonso, 2009, p. 56). 
As competiçôes passam a compor o cenário educativo, como já foram analisadas em outros estudos (cf. Afonso, 2007; Souza \& Oliveira, 2010) que antecedem a lógica das nossas inferências, também fortemente evidenciadas nos discursos das professoras entrevistadas. Uma das professoras cita as placas colocadas na entrada das escolas. Essas placas servem para informar a população sobre os resultados que as escolas alcançaram nas avaliaçóes, configurando-se como uma forma de incentivar a competitividade e pressionar diretores e professores pela busca de melhores resultados, sem, entretanto, mostrar os fatores intra-escolares que tenham contribuído para tal resultado. O descontentamento com a afixação destas placas nas entradas das escolas é perceptível:

Aqui faz uma reuniáo com os pais, aí mostra aqueles gráficos... Geralmente quando sai o resultado do IDEB mostra tudo «tipo, nossa escola deveria atingir a meta tal e atingimos essa meta tal». E os pais aqui têm outras realidades, aqui são analfabetos funcionais, os pais náo conseguem orientar o filho numa atividade. Para eles é uma coisa sem sentido, interpretar gráfico não faz sentido. A única coisa que eles sabem é se a escola melhorou ou não. A gente coloca a placa, a tal da placa. Mostramos o índice do estado de Minas Gerais, o índice no município e o índice da escola.

Uma das entrevistadas ressalta o fato de a competição e responsabilização acontecer entre os profissionais da mesma instituição, uma vez que há benefícios e incentivos financeiros caso as metas sejam cumpridas e os resultados alcançados com sucesso. Ou seja, resumidamente, os espaços são abertos para a realização de pressôes educativas dentro do próprio sistema educacional (Afonso, 2007).

Outro aspecto que vale ressaltar é o referente à autonomia das professoras. Elas se queixam de gastarem um período razoável de tempo com treinamento de questôes, enquanto poderiam estar utilizando-o para desenvolverem o seu planejamento - fato esse que confirma a intervenção da lógica avaliativa até na sua atuaçáo dentro da própria sala de aula e na aprendizagem do aluno, onde o «aprender» por repetição ou treino ocupa o lugar da criatividade, inventividade, ludicidade, táo importantes para o desenvolvimento da criança.

Ainda que nas entrevistas algumas demonstrem criticidade em relação ao ranqueamento e à responsabilização que recai sobre elas, e tentem restabelecer a autonomia que elas mesmas afirmam que deveriam exercer em suas salas de aula, a «autonomia da escola pública, mais retórica do que real, acabou por ser mais um pretexto para a avaliação e responsabilização dos atores educativos» (Afonso, 2007, p. 17). 
Essa autonomia mediada se relaciona com as atitudes que servem de reforço para alcançar um bom resultado nas avaliaçóes. A realidade evidenciada por uma professora quando nos fez a seguinte declaração «já vou dando simulados durante o ano, até para os alunos se acostumarem com questóes, com a forma como são as provas», é reafirmada também na percepção de outra entrevistada dizendo que «eu tenho que passar um longo período treinando meu aluno pra prova». São os mecanismos artificiais de adequação curriculares, fortemente empregados pelas docentes, ainda que demonstrem grande insatisfação ao admitirem essa atitude.

Isso nos permite inferir que o poder coercitivo do Estado recai sobre elas, moldando suas práticas e interferindo no próprio planejamento enquanto ato pedagógico fundamental da prática docente.Porém, é importante salientar que, embora a maioria dos resultados aponte para um balanço negativo em relação à forma como as avaliaçóes externas exercem sua influência no trabalho das docentes, elas também ressaltam como ponto positivo o fato de o Estado se importar em avaliar a qualidade da educação, e que os descritores utilizados para nortear as avaliaçôes acabam por orientá-las em relação ao currículo praticado, fator relevante para imprimirem certa coerência ao seu trabalho.

Ao elencar os aspectos positivos das avaliaçóes externas, uma das professoras nos diz o seguinte, referindo-se aos sujeitos que elaboram os testes padronizados: «eles tentam focar as habilidades que as crianças devem vencer, é naquele direcionamento ali». Quando ela aponta a questáo do direcionamento, sua fala encontra ressonância na fala de outra docente, que destaca a importância dos descritores para o seu planejamento de ensino.

Eu gosto sempre de dar uma avaliação diagnóstica para os alunos e eu foco sempre nos descritores do PROALFA porque eles são bons pra você perceber a dificuldade. A provinha Brasil, a gente pega a análise dela pra ver a dificuldade deles.

Quando analisamos tais falas percebemos, além da postura crítica que as docentes têm em relação à forma como as avaliações externas são impostas, a carga simbólica e real que o processo avaliativo externo tem para induzir um remodelamento das avaliaçóes internas e do planejamento diário. Além disso, uma das professoras destaca o processo dessas avaliaçóes para o aprendizado social, como por exemplo, o fato de que ao aplicarem esse tipo de prova a seus alunos, estes já iniciarão o processo de "autoconhecimento», de aprenderem a lidar com o próprio nervosismo.

A participação docente no cenário das avaliaçóes externas pode ser observada na fala da professora que declarava sua angústia em relação às burocracias 
embutidas na realização das provas. Por meio do relato podemos perceber também a noção de qualidade que ela pressupóe sobre o processo avaliativo.

Eu acho que são burocráticas essas provinhas, porque a única pessoa que pode avaliar o índice de desenvolvimento dos meus alunos sou eu, e isso não acontece. $\mathrm{O}$ IDEB não mede coisa nenhuma! Às vezes eles vão mal na prova, mas tinham total capacidade de fazer a prova. Pro IDEB ele é incapaz, pra mim ele é totalmente capaz. Então IDEB não mede realmente o nível de conhecimento! É impossível uma pessoa que elabora isso ser uma pessoa da educação. Pode até ter formação, mas nunca entrou numa sala de aula, não é possível, gente! Não que as provas sejam mal elaboradas, sabe! Eu acho assim: que eles tentam focar as habilidades que as crianças devem vencer, é naquele direcionamento ali, mas não funciona pelo tamanho das provas, o jeito que ela é aplicada.

Destaca-se que, ao mesmo tempo em que a professora reconhece a importância do direcionamento para o currículo que ela deveria seguir com seus alunos, ela questiona a forma como é aplicada e quem são esses agentes que pensam, organizam e planejam o processo avaliativo à revelia da escola. Ela nos fala dos quesitos que não podem ser mensurados em uma avaliação como essa; nos fala de algo mais tangível, que deve ser diretamente relacionado à vida da sala de aula e tudo que a envolve.

Em seguida, ela acrescenta que «quem elaborou isso não pensa na qualidade do que o aluno vai aprender, só se pensa na quantidade [...]». E, nessa perspectiva, sua compreensão coaduna com a discussão que incitamos sobre o padrão de qualidade educacional inserido nesse modelo de política, em contraposiçáo ao pressuposto gramsciano que ora defendemos.

Tal análise nos faz refletir que esse é um fator que merece ser esclarecido, tendo em vista a crença oficial de ter o IDEB como indicador de dados e metas a serem cumpridas para a melhoria da qualidade do ensino. Segundo o Ministério da Educação,

o Índice de Desenvolvimento da Educação Básica (IDEB), foi criado em 2007, pelo Instituto Nacional de Estudos e Pesquisas Educacionais Anísio Teixeira (INEP), formulado para medir a qualidade do aprendizado nacional e estabelecer metas para a melhoria do ensino (Brasil, 2015, n.p.).

Sobre tais objetivos, cabe perguntarmos: a serviço de quem está essa suposta qualidade? Que qualidade é essa que não envolve a participação docente? Entendemos que estas questóes são particularmente importantes do ponto de vista do projeto de escola e de naçáo que queremos, sobretudo para os rumos que a política avaliativa percorre. 


\section{Consideraçóes}

Ainda que não se tenha evidenciado neste trabalho a importância das avaliaçóes externas, fazemos a ressalva de que náo invalidamos sua legitimidade. Reconhecemos que se tornaram o centro irradiador das atuais políticas educacionais, mas que, para além de buscarem determinar a qualidade do ensino público, oferecerem subsídios capazes de direcionar a prática docente de forma perversa, tendo em vista, principalmente, que desconsideram o contexto escolar e a participação docente. Configuram-se, assim, como mais uma forma de regulação educativa utilizada pelo Estado.

Nessa perspectiva, destacamos as relaçóes conflituosas às quais os docentes são expostos. Se por um lado foi possível perceber a importância que atribuem às avaliaçóes externas, por outro evidenciou-se como sua autonomia é cerceada, já que modelam sua prática pelo processo de treinamento de questôes para obter bons resultados, almejando alcançar benefícios pela via de uma prática transpassada pelo modelo gerencialista implementado.

As críticas a este modelo de política surgiram, na maioria das vezes, em relação à forma como estas avaliações são implementadas e desenvolvidas, tendo como justificativa que o efeito desta modalidade avaliativa não é compatível com os objetivos educacionais, e só quer, na verdade, informar metricamente os resultados, deslocando o eixo dos procedimentos sempre para o desfecho do processo.

Por fim, neste trabalho são apresentadas as perspectivas dos profissionais que atuam em sala de aula, local onde recaem as maiores cobranças por parte da administração da escola e dos agentes externos a ela. Consideramos, então, que a qualidade da educação deve ser estabelecida pela valorização do professor, e não por cobranças que extrapolam as incontáveis metas do IDEB.

Evidentemente, não temos respostas prontas para tantas dúvidas iniciais e novas questôes que foram surgindo, mas acreditamos que o discurso sobre as avaliaçóes externas na atuação docente necessita, portanto, incorporar maior análise social e política, pois a partir dela talvez seja possível visualizar as relaçôes antagônicas que existem dentro da escola, de forma que evidenciem mais o processo e os desafios enfrentados pelos professores.

As discussóes durante a realização da pesquisa nos fizeram perceber que a escola foi e ainda é um território de disputa política. A política está na essência da educação - a política que nos torna sujeitos - por isso enfatizamos a importância de estudos desse cunho para compreender a educação nesse espaço de inquietude que, cada vez mais, é vital aos processos humanos. 


\section{REFERÊNCIAS BIBLIOGRÁFICAS}

Afonso, A. J. (1999). Estado, mercado, comunidade e avaliação: esboço para uma rearticulação crítica. Educação \& Sociedade, 69,139-164. https://doi. org/10.1590/S0101-73301999000400007

Afonso, A. J. (2007). Estado, políticas educacionais e obsessão avaliativa. Contrapontos, 7(1), 11-22. Itajaí.

Afonso, A. J. (2009). Nem tudo o que conta em educação é mensurável ou comparável. Crítica à accountability baseada em testes estandardizados e rankings escolares. Lusófana de Educaçâo, 13, 13-29.

Afonso, A. J. (2010). Avaliação educacional. In D. A. Oliveira, A. M. C. Duarte, L. M. F. Vieira. Dicionário: trabalho, profissáo e condição docente. Belo Horizonte: UFMG/Faculdade de Educação.

Afonso, A. J. (2014). Questôes, objetos e perspectivas em avaliação. Avaliação, 19(2), 487-507. Campinas SP. https://doi.org/10.1590/S141440772014000200013

André, M. E. D. A. \& Ludke, M. (1986). Pesquisa em educação: abordagens qualitativas. São Paulo: E. P. U.

Bogdan, R. C. \& Biklen, S. K. (1994). Investigação qualitativa em educação: uma introdução à teoria e aos métodos. Portugal: Porto Editora.

Brasiel, M. E. C. P. \& Baquim, C. A. (2014). Avaliaçôes externas de matemática na microrregião de Ubá: estudo comparativo das redes públicas de ensino. Relatório de Iniciação Científica. Viçosa, UFV.

Brasil (2013). Ministério da Educaçáo. Portaria no 482, de 7 de junho de 2013. Dispõe sobre o Sistema de Avaliação da Educação Básica - SAEB. Brasília: MEC. Recuperado em 19 de maio de 2015 de http://portal.inep.gov.br/ web/saeb/semelhancas-e-diferencas

Brasil (2015) Instituto Nacional de Estudos e Pesquisas Educacionais Anísio Teixeira. IDEB - Apresentação. Recuperado em 19 de maio de 2015 de http://portal.mec.gov.br/index.php?Itemid=336

CAED/UFJF (2014). Avaliação. Recuperado em 15 de maio de 2014 de http:// www.portalavaliacao.caeduff.net/

Calderano, M. de A. (coord.) (2012). A formação, o trabalho dos docentes que atuam no ensino fundamental e a avaliação sistêmica das escolas mineiras: interpretando os constructos junto aos professores. Juiz de Fora: UFJF.

Chueiri, M. (2008). Concepçôes sobre a atuação escolar. Estudos em Avaliaçấo Educacional, 19(39), 49-64. São Paulo. https://doi.org/10.18222/ eae193920082469 
Dallari, D. A. (2007). Elementos da teoria geral do Estado. 26. ed. São Paulo: Saraiva.

Duarte, A. (2010). Tendências das reformas educacionais na América Latina para a Educação básica nas décadas de 1980 e 1990. In L. M. Faria Filho et al. (orgs.), Reformas educacionais no Brasil: democratização e qualidade da escola pública (pp. 161-185). Belo Horizonte: Mazza Ediçóes.

Freitas, K. S. (2009). Progestâo: como articular a gestáo pedagógica da escola com as políticas públicas da educação para a melhoria do desempenho escolar? Módulo X. Brasília: CONSED.

Gramsci, A. (2001). Os intelectuais. O princípio educativo. Jornalismo. In C. N. Coutinho (org.), Antonio Gramsci: cadernos do cárcere 2. 2. ed. Rio de Janeiro: Civilização Brasileira.

Lakatos, E. M. \& Marconi, M. de A. (2010). Fundamentos de metodologia cientifica. Sáo Paulo: Atlas.

Ribeiro, B. B. D. (2002). A função social da avaliação escolar e as políticas de avaliação da educação básica no Brasil nos anos 90: breves considerações. Recuperado em 4 de abril de 2014 de revistas.ufg.br/índex.php

Santos, J. C. (2013). Iniciação docente: principais desafios encontrados pelos professores recém inseridos na sala de aula. In M. A. Calderano et al. (orgs.), O que o IDEB náo conta? Processos e resultados alcançados pela Escola Básica (pp. 51-72). Juiz de Fora: UFJF.

Sarrico, C. S. (2014). Avaliação e gestão do desempenho de escolas em Portugal: o juízo, o juiz, o modelo do juiz e o julgado. In Maria de Lurdes Rodrigues (org.), 40 anos de políticas de educação em Portugal: conhecimento, atores e recursos (pp. 271-286). Coimbra: Almedina.

Sousa, S. Z. \& Oliveira, R. P. (2010). Sistemas estaduais de avaliação: uso dos resultados, implicaçóes e tendências. Cadernos de Pesquisa, 40(141), 793822. São Paulo. Recuperado em 10 de abril de 2014 de http://www.producao.sp.br/bitstream/handle/BDPI/6411/art_SOUSA_Sistemas_estaduais_de_avaliacao_uso_dos_resultados_2010.p?sequence=1\&isAllow ed $=y$

Vianna, H. M. (1995). A Avaliação Educacional: uma perspectiva histórica. Estudos em Avaliação Educacional, 12, 7-24. https://doi.org/10.18222/ eae01219952297 